\title{
DYNAMICS OF PROPELLING ELECTRIC POWER PLANTS OF ELECTRIC SHIPS' PROPULSIVE COMPLEXES
}

\section{Yarovenko V. A.}

\section{INTRODUCTION}

One of the main qualities that determined the reason for the high interest in modern electric propulsion systems is the high maneuverability of ships equipped with propelling electric power plants. For a wide class of vessels, maneuvers are one of the main operating modes. The behavior of electric ships in maneuvers - during the most difficult and critical operations - primarily determines the structure of a propelling electric power plants, its equipment, configuration, etc.

Traditionally, the design of propeller electric plants was carried out under the assumption that the speed of the vessel is constant. With this approach, it is possible to represent the dependence of the moment of resistance on the shaft of the propeller motors as a quadratic function of the propeller angular rotation speed, and to separate the propeller plant from propulsors and from the hull. This technique allows us to consider the propulsion system separately from the vessel, thereby simplifying the design tasks. However, the criteria characterizing the quality of the design of the propulsion system inevitably are indicators characterizing the operation of the propulsion system.

Modern electric ships have a high degree of power-to-weight ratio, as a result of which, in maneuvering modes, the durations of transients in a propelling electric power plant (PEPP) are commensurable with the durations of transients in the remaining components of the ship propulsion complex ${ }^{12}$.

Therefore, when analyzing dynamic modes of operation, assumptions about the constancy of the speed of the vessel in transitional regimes of the PEPP (as well as the assumption of the constancy of the frequency of propeller rotation in the analysis of the motion of the vessel) are not acceptable. Moreover, it should be borne in mind that with a systematic approach to the design of propulsion plants (junior system), first of all, it is necessary to satisfy the requirements of the older system (vessel), for operation of which the

${ }^{1}$ Himmelblau D. (1975) Prikladnoe nelineynoe programmirovanie [Applied nonlinear programming]. Moskva : Mir, 1975. $534 \mathrm{p}$.

2 Yarovenko V. A. (1999) Raschet i optimizatsiya perekhodnykh rezhimov propul'sivnykh kompleksov elektrokhodov [Calculation and optimization of transient modes of propulsive complexes of electric ships]. Odessa : Lighthouse, 1999. 188 p. 
propulsion plant is intended ${ }^{3}$. In accordance with this, comparative assessments of the design quality, PEPP should be carried out first of all according to the criteria of the vessel, in particular, according to its maneuverability characteristics. The design, and then the optimization of a power plant with this approach is carried out, in fact, according to the "final result". This contributes to the creation of reliable, highly maneuverable, economical vessels with electric propulsion.

From what has been said, it follows that when designing a propelling electric power plant, it should be considered as an integral part of a single ship propulsive complex, which includes both an electric propelling plant, propellers, and a ship's hull. In this paper, some issues of a systematic approach to the design of electric power plants on the ships with electric propulsion are considered.

\section{THE MATHEMATICAL MODEL OF THE ELECTRIC SHIPS' PROPULSIVE COMPLEX}

Vessels with electric propulsion, as a rule, have several power circuits, at the output of which there are propeller motors (PM). One of the promising options is a propelling electric drive based on asynchronous frequencycontrolled PMs.

The generalized structural diagram of such a propulsive complex ${ }^{4}$ is shown in Fig. 1. Each power circuit includes: a heat engine $-D$, a synchronous generator $-G$, a frequency inverter of electricity $-S E$, an asynchronous propeller motor $-M$, a speed controller of the heat engine $-D R$; a synchronous generator voltage regulator $-G E$, a propeller $-P$. Propulsion system also includes a rudder $-R$ and a hull. The main output parameters, control signals and feedback signals are: $\omega_{D}$ and $P_{D}$ - angular rotation speed and power of heat engines; $U_{G}$ and $I_{G}$ - voltage and current at the output of the generator; $U_{M}$ and $I_{M}$ - voltage and current of propeller motors; $M_{M}$ and $\omega_{M}$ are the torque and angular rotation speed of the $P M s$ (and propellers).

${ }^{3}$ Yarovenko V. A., Chernikov P. C. (2017) Metod rascheta perekhodnykh rezhimov grebnykh elektroenergeticheskikh ustanovok elektrokhodov [The method of calculating the transitional regimes of rowing electric power plants of electric ships]. Electrotechnika $i$ elektromekhanika. 2017. No. 6. Pp. 32-41. DOI: 10.20998/2074-272X.2017.6.05.

${ }^{4}$ Yarovenko V. A., Zaritskaya E. I., Chernikov P. C. (2017) Otsenka manevrennykh kharakteristik elektrokhodov na nachal'nykh stadiyakh ikh proektirovaniya [Assessment of the maneuverability characteristics of electric ships at the initial stages of their design]. Visnik NTU "KhPI". Seriya "Electric Machines and Electric Power Engineering. Kharkiv: NTU “KhPI”, 2017. No. 1 (1223). Pp. 57-63. 


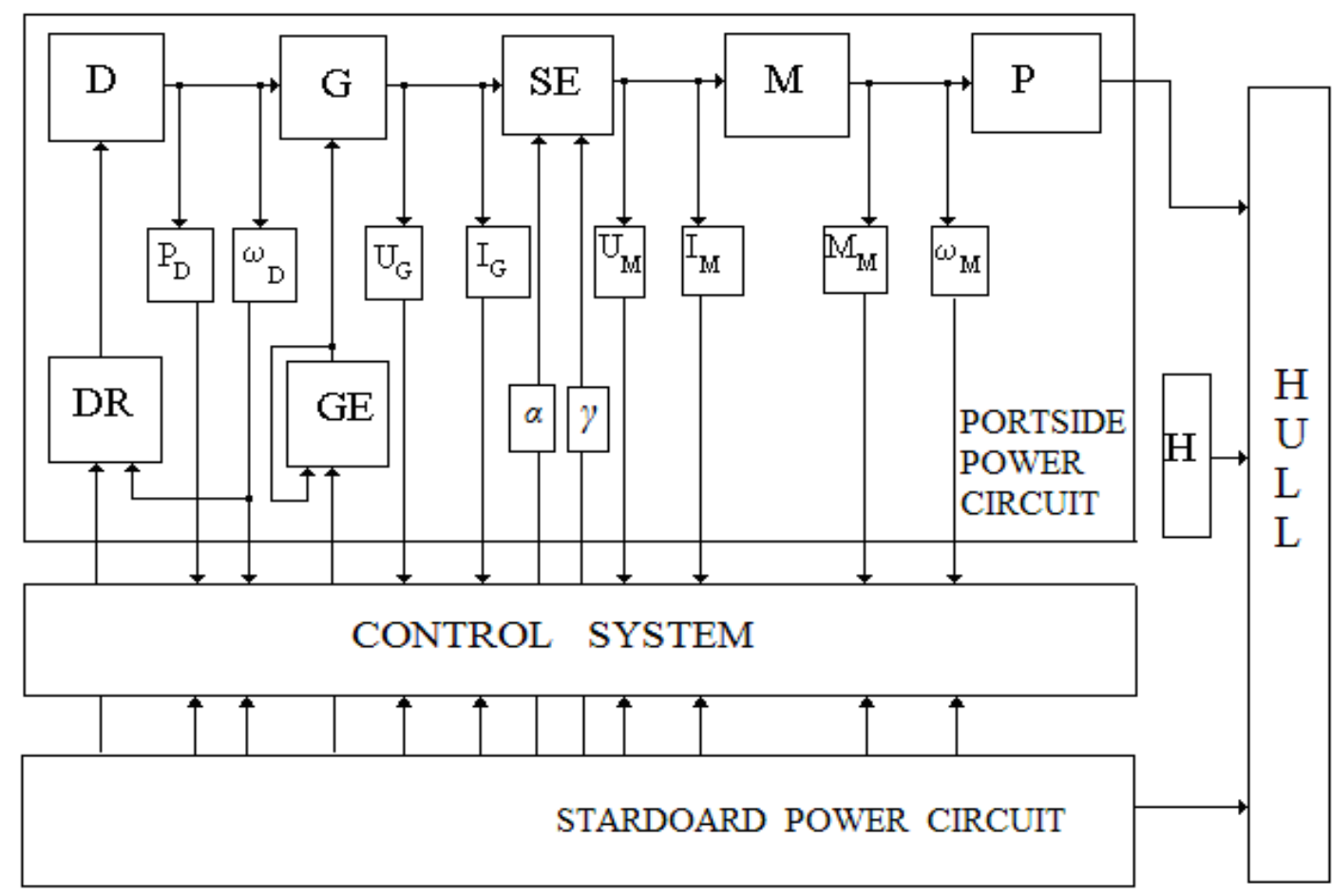

Fig. 1. The structural diagram of the propulsive complex of the electric ship

Based on the structural diagram, a mathematical model and a method for calculating transient operation modes of propulsive complexes on maneuvers have been developed. The mathematical model is presented in dimensionless units. In the process of its development, criteria for dynamic similarity were identified and generalized dimensionless parameters of the propulsive complex were found ${ }^{5}$. This opens up wide possibilities for conducting broad generalizations of the results obtained and for developing further recommendations acceptable for a large class of vessels. Complexes with the same values of similarity criteria and with equal values of dimensionless parameters will have the same values (in relative units) of the corresponding quality indicators.

Heat engine and speed controller.

Heat engine equation

$$
\frac{d \overline{\omega_{D}}}{d T}=N_{D}\left(\overline{M_{D}}-\overline{M_{G}}\right)
$$

${ }^{5}$ Yarovenko V. A., Zaritskaya E. I., Chernikov P. C. (2017) Otsenka manevrennykh kharakteristik elektrokhodov na nachal'nykh stadiyakh ikh proektirovaniya [Assessment of the maneuverability characteristics of electric ships at the initial stages of their design]. Visnik NTU "KhPI". Seriya "Electric Machines and Electric Power Engineering. Kharkiv: NTU “KhPI”, 2017. No. 1 (1223). Pp. 57-63. 
where $T=\frac{v_{0}}{L} t-$ the relative time; $v_{0}-$ the speed of the vessel in the basic mode with the rated power of the propulsion motors (hereinafter, all the indicators indicated by the index " 0 " refer to the basic mode of operation corresponding to the movement of the vessel at the rated speed with the rated power of the electric propelling plant); $L$ - the length of the vessel; $t$ - the current time; $J_{D}-$ the moment of inertia of the engine and generator reduced to the shaft of the heat engine;

$N_{D}=\frac{M_{D 0} L}{J_{D} \omega_{D 0} v_{0}}-$ dynamic similarity criterion.

The torque of a heat engine $\overline{M_{D}}$ can be represented as the relative movement of the fuel pump rail

$$
\overline{M_{D}}=\overline{\xi_{D}} \text {. }
$$

Heat engine power

$$
\overline{P_{D}}=\overline{M_{D}} \overline{\omega_{D}} \text {. }
$$

The equations of transients in the speed controller of a heat engine, taking into account the rigid and flexible feedbacks, and taking into account the operation of the active power distribution system (with parallel-acting GA), can be represented as

$$
\frac{d \overline{\xi_{D}}}{d T}=K_{P}\left(1-\left(\overline{\omega_{D}}-\Delta \overline{\omega_{H}}\right)\right)-K_{F b} \overline{\Delta \xi_{D}}-K_{i s} \overline{\Delta \xi_{D}},
$$

where $K_{P}, K_{F b}, K_{i s}$ - gain coefficients according to an adjustable value (change in the rotation speed of a heat engine), rigid feedback and flexible (isodromic) feedback, respectively; $\Delta \omega_{H 1}-$ the difference in the angular frequencies of rotation of the generators.

Synchronous generator and automatic voltage regulation system.

In contrast to the "classical" description of a synchronous generator $(S G)$, processes that are incommensurable with the time constants of the main components of the electric ship's propulsive complex, namely, transformer EMFs in stator windings, are not taken into account here. In view of the smallness, we neglect the active resistance of the armature, the mutual inductance, and also the flux linkages of the damper windings. 
The combined system of automatic voltage regulation of synchronous generators includes a regulation contour of reactive power distribution (with generator sets operating in parallel). Generator electric magnetic moment

$$
\overline{M_{G}}=-K_{G 1} \overline{I_{G}^{2}} \sin \psi_{G} \cos \psi_{G}+K_{G 2} \overline{I_{f}} \overline{I_{G}} \cos \psi_{G},
$$

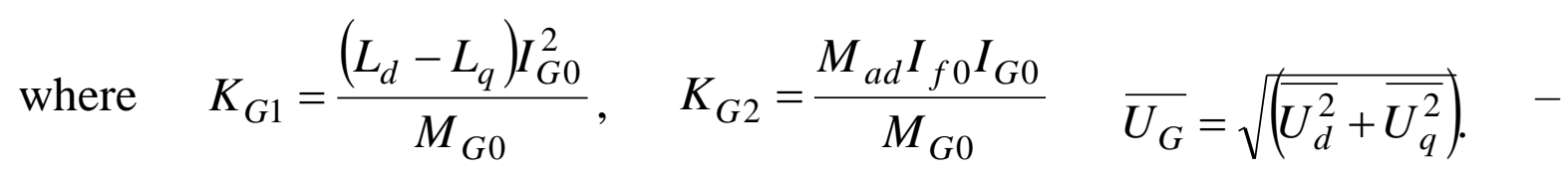
dimensionless parameters; $L_{d}$ и $L_{q}$ - the inductances of the self-induction of the armature winding along the internal coordinates $d$ and $q ; M_{a d}-$ mutual induction inductance along the $d$ axis.

Generator output voltage

$$
\overline{U_{G}}=\sqrt{\left(\overline{U_{d}^{2}}+\overline{U_{q}^{2}}\right)}
$$

Generator active power

$$
\overline{P_{G}}=\overline{U_{G}} \overline{I_{G}} \cos \varphi_{G}
$$

Generator voltages ( $d-q$ internal coordinates)

$$
\begin{gathered}
\overline{U_{d}}=-K_{d 1} \overline{I_{G}} \cos \psi_{G}, \\
\overline{U_{q}}=-K_{q 1} \overline{I_{G}} \sin \psi_{G}+K_{q 2} \overline{I_{f}},
\end{gathered}
$$

where $I_{f}$-is generator field current

$$
\begin{gathered}
\frac{d \overline{I_{f}}}{d T}=N_{f}\left(K_{f 1} K_{U q} \overline{U_{q}}+K_{f 2} K_{I d} \overline{I_{d}}-K_{f 3} K_{U}\left(\overline{U_{G}}-\left(1-\Delta \overline{U_{H 1}}\right)\right)-\overline{I_{f}}\right),(10) \\
N_{f}=\frac{L U_{f 0}}{L_{f} I_{f 0} v_{0}}-\text { is the dynamic similarity criterion; } L_{f} \text { is the inductance }
\end{gathered}
$$
of the self -induction of field winding; $U_{f}$ and $I_{f}$ - voltage and current of the field winding; $K_{f 1}, K_{f 2}, K_{f 3}$ - gain coefficients for the main signal, for the disturbing effect and for the deviation of the controlled variable, respectively; $K_{d 1}, K_{q 1}, K_{q 2}, K_{U q}, K_{I d}, K_{U}$ - dimensionless parameters.

Generator currents (internal coordinates $d-q$ ): 


$$
\begin{aligned}
& \overline{I_{d}}=-\overline{I_{G}} \sin \psi_{G}, \\
& \overline{I_{q}}=\overline{I_{G}} \cos \psi_{G} .
\end{aligned}
$$

The phase angle between the EMF vector $\overline{E_{G}}$ and the generator current vector $\overline{I_{G}}$ is determined from the vector diagram of the synchronous generator taking into account its operation on the frequency converter.

Frequency converter.

The frequency converter and the frequency converter with an autonomous voltage inverter are considered as a converter. We consider it as an inertialess quantizer of electricity with ideal valves. We do not take into account the electromagnetic processes occurring in it. We believe that the current at the output of the converter is continuous, and the converter itself does not go beyond the normal load range.

In this case, the dependence of the output voltage on the input voltage can be represented as

$$
\overline{U_{M}}=\gamma \overline{U_{G}}
$$

where $U_{M}$ - is the voltage of the $P M ; \gamma$ - is the relative voltage control signal (one of two control signals of operation of frequency-controlled $P M S$ ).

Propulsion motor.

The exact classical diagram of an asynchronous motor replacement is the basis of mathematical model of an asynchronous frequency-controlled $P M$. This determines the necessary assumptions and simplifications. The voltage across the stator clamps is considered to be sinusoidal. Machine steel saturation is not considered. The distribution of flow along the arc of the air gap is assumed to be sinusoidal. Steel losses in the stator are taken into account approximately, and losses in the rotor are not taken into account.

Equation of $P M$ dynamics

$$
\frac{d \overline{\omega_{M}}}{d T}=N_{M}\left(\overline{M_{M}}-\overline{M_{P}}\right)
$$

where $N_{M}=\frac{M_{M 0} L}{J_{M} \omega_{M 0} v_{0}}-$ dynamic similarity criterion.

PM moment

$$
\overline{M_{M}}=K_{M} \overline{I_{M}} \overline{\Phi_{M}} \cos \varphi_{M}
$$


Motor current

$$
\overline{I_{M}}=C_{M 24} \gamma \frac{1}{\sqrt{C_{M 17}+C_{M 18} \alpha^{2}+\frac{C_{M 21}+C_{M 22} \alpha^{2}}{\left(C_{M 19} \alpha-C_{M 20} \overline{\omega_{M}}\right)^{2}}+\frac{C_{M 23} \alpha}{C_{M 19} \alpha-C_{M 20} \overline{\omega_{M}}}}} .
$$

MP magnetic flow

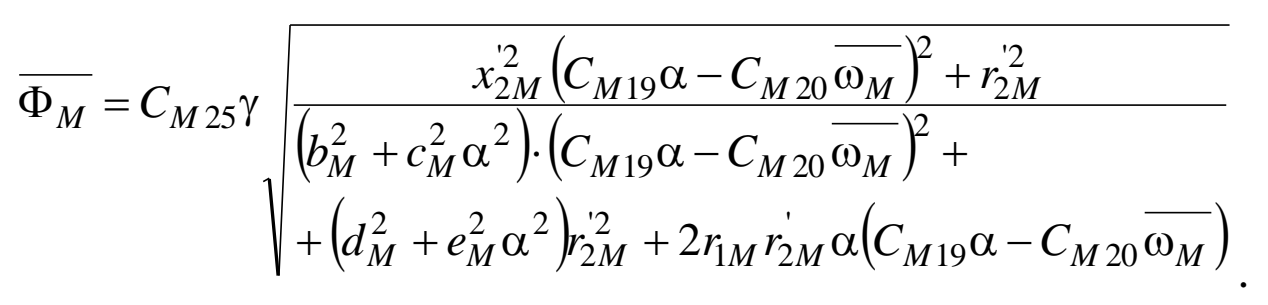

Motor power coefficient

$$
\cos \varphi_{M}=\frac{1}{\sqrt{1+C_{M 26}\left(C_{M 19} \alpha-C_{M 20} \overline{\omega_{M}}\right)^{2}}} .
$$

Here: $J_{M}-$ is the moment of the motor inertia ; $K_{M}-$ is a constant design coefficient; $\omega_{1 M n}-$ is the rotation frequency of the stator magnetic field; $r_{1 M}$ and $r_{2 M}^{\prime}$ - are the active resistances of the $A M$ stator and rotor (reduced); $x_{1 M}$ and $x_{2 M}^{\prime}$ - inductance of the $A M$ stator and rotor (reduced); $x_{0 M}$ - is the inductive magnetization resistance; $\beta_{M 0}$ - absolute slip of the AM rotor; $C_{M 17}$, $C_{M 22}, C_{M 18}, C_{M 19}, C_{M 20}, C_{M 21}, C_{M 23}, C_{M 24}, C_{M 25}, C_{M 26} b_{M}, c_{M}, d_{M}$ , $e_{M}, \tau_{1 M}, \tau_{2 M}, \tau_{M}$ - dimensionless parameters of the complex are calculated ${ }^{6}$ from the corresponding relations.

Propellers.

The hydrodynamic reverse characteristic of the propeller, taking into account the movement of the vessel along a curved path, can be represented as a parabolic polynomial ${ }^{7}$.

Propeller moment

$$
\overline{M_{P}}=a_{21}{\overline{\omega_{P}}}^{2}+b_{21} \overline{\omega_{P}} \overline{v_{e}}+c_{21}{\overline{v_{e}}}^{2}+a_{M} \bar{v}^{2} \operatorname{tg}^{2} \alpha_{C K}
$$

propeller thrust

${ }^{6}$ Nebesnov V. I. (1965) Voprosy sovmestnoy raboty dvigateley vintov i korpusa sudna [Issues of joint work of propeller engines and hull]. L.: Shipbuilding, 1965. 247 p.

7 Pershits R. Ya. (1983) Upravlyaemost' i upravlenie sudnom [Manageability and control of the vessel]. L.: Shipbuilding, 1983. 272 p. 


$$
\overline{P_{P}}=a_{11}{\overline{\omega_{P}}}^{2}+b_{11} \overline{\omega_{P}} \overline{v_{e}}+c_{11}{\overline{v_{e}}}^{2}+a_{P} \bar{v}^{2} t g^{2} \alpha_{C K}
$$

where: $\overline{\omega_{P}}-$ is the angular velocity of propeller rotation; $\overline{v_{e}}-$ is the rate of water leakage onto the propeller; $a_{21}, a_{11}, b_{21}, b_{11}, c_{21}, c_{11}$ - are the coefficients of the universal characteristic of the propeller (constant in certain measurement ranges $\overline{\omega_{P}}$ and $\left.\overline{v_{e}}\right) ; a_{M}, a_{P}-$ are constant coefficients; $\alpha_{C K}-$ is the angle of inclination of the water flow.

The electric ship's hull.

The movement of the vessel along the free surface of the water in the associated coordinate system GXYZ is considered, the origin of which coincides with the center of gravity of the vessel $G$. The plane $G X Y$ is parallel to the main plane of the vessel, the axis $G X$ is located in the diametrical plane and is directed to the bow, the axis $Z Y$ is on the starboard side, the axis $G Z$ is vertically up. The added moment $\lambda_{26}$ is neglected $^{8}$.

The components of the vessel speed along the $X, Y$ axes and the speed of rotation around the $Z$ axis are:

$$
\begin{aligned}
& \frac{d \overline{v_{X}}}{d T}=C_{\lambda 2} \overline{v_{Y}} \overline{\Omega_{Z}}+N_{X}\left\{\sum_{J} K_{P j} \overline{P_{e j}}-C_{R X} \beta_{R P} \overline{v^{2}}-\overline{R_{X}}\right\} ; \\
& \frac{d \overline{v_{Y}}}{d T}=-\frac{1}{C_{\lambda 2}} \overline{v_{X}} \overline{\Omega_{Z}}+\frac{N_{X}}{C_{\lambda 2}}\left\{\sum_{J} K_{P j} \alpha_{j z} \overline{P_{e j}}-C_{R Y} \beta_{R P} \overline{v^{2}}-\overline{R_{Y}}\right\} ; \\
& \frac{d \overline{\Omega_{Z}}}{d T}=-\frac{N_{\Omega}}{N_{X}} C_{\lambda 21} \overline{v_{X}} \overline{v_{Y}}+N_{\Omega}\left\{\begin{array}{c}
\sum_{j}^{\sum_{j} K_{P j} h_{P j} \overline{P_{e j}}}+\left(\overline{M_{\Pi Z}}-\overline{M_{\Delta Z}}\right)+C_{R Y} \overline{X_{R}} \beta_{R P} \overline{v^{2}}
\end{array}\right\},
\end{aligned}
$$

where:

- longitudinal steering force

$$
\overline{R_{X}}=\left\{C_{11} \cos 1,5 \beta_{d r}-C_{12} \sin ^{4} 1,5 \beta_{d r}+C_{13}\left(\frac{2 \beta_{d r}}{\pi}\right)^{3}\right\} \overline{v^{2}} ;
$$

- lateral steering force

$$
\overline{R_{Y}}=\left\{C_{21} \sin 2 \beta_{d r} \cos \beta_{d r}+C_{22} \sin ^{2} \beta_{d r}+C_{23} \sin ^{4} 2 \beta_{d r} \overline{\kappa^{2}} ;\right.
$$

${ }^{8}$ Zubarev Yu. A., Sobashnikov A. D., Yukhnovich V. A. (1976) Raschet sudovykh avtomatizirovannykh sistem metodom aktivnogo planirovaniya eksperimenta [Calculation of shipboard automated systems by the method of active experiment planning]. L.: Shipbuilding. 1976. 96 p. 
- turning moment

$$
\begin{gathered}
\overline{M_{\Pi Z}}-\overline{M_{д Z}}=\left[\begin{array}{l}
C_{61} \sin 2 \beta_{\partial p}+C_{62} \sin \beta_{\partial p}+ \\
+C_{63} \sin ^{3} 2 \beta_{\partial p}+C_{64} \sin ^{4} 2 \beta_{\partial p}
\end{array}\right] \cdot \overline{v^{2}}-C_{65} \overline{\Omega_{Z}} \overline{v^{2}} \\
; \\
C_{\lambda 2}, C_{\lambda 21}, C_{R X}, C_{R Y}, C_{11}, C_{12}, C_{13}, C_{21}, C_{23}, C_{61}, C_{62}, C_{63}, C_{64}, C_{65} \\
\text { - dimensionless parameters; }
\end{gathered}
$$

$$
N_{X}=\frac{L \sum K_{P j} P_{e j 0}}{\left(m+\lambda_{11}\right) v_{0}^{2}}, N_{\Omega}=\frac{L^{3} \sum K_{P j} P_{e j 0}}{2\left(J_{Z}+\lambda_{66}\right) v_{0}^{2}}
$$

criteria for dynamic similarity; $X_{R}$ - distance from the center of the coordinate system to the steering wheel; $P_{e j}$ and $K_{P j}$-are the effective propeller thrust and its share in the total flow, respectively; $m$ - is the mass of the vessel; $\rho-$ is the specific gravity of water; $\lambda_{11}$ and $\lambda_{22}$ - are the attached masses of water along the $X$ and $Y$ axes; $\lambda_{66}-$ attached moment of inertia of water; $\mu_{r x}-$ is the coefficient of resistance of the rudder $\mu_{K}$ - is the coefficient of lateral force of the rudder; $\psi-$ is the angle of the course; $S_{C}$ - reduced rudder area; $c_{4}$ - is the coefficient of longitudinal positional force of water resistance; $C_{Y}^{\beta}$, $c_{2}, c_{3}$ - hull strength factors; $m_{1}, m_{2}, m_{3}, m_{4}$ - are the coefficients of the positional moment of resistance; $F_{D}$ - reduced area of the submerged part of the vessel diametrical plane; $M_{P Z}$ and $M_{D Z}$ - positional and damping moments of resistance; $C_{m 0}{ }^{\omega}$ - coefficient of damping moment of resistance; $\beta_{d r}$ - is the drift angle; $J_{Z}-$ moment of inertia of the vessel during rotation around the $Z$ axis.

Rudder angle

$$
\beta_{R P}=K_{R} \beta_{R}-\chi_{C}\left(\operatorname{arctg} \beta_{d r}-\varepsilon \frac{\overline{\Omega_{Z}}}{\bar{v}}\right),
$$

where $\beta_{R}$ - is the turning angle of the rudder; $\chi_{C}-$ reduced coefficient of influence of the hull and propellers on the rudder; $\varepsilon-$ is the value determined by the ratio $l_{R} / L\left(l_{R}-\right.$ is the distance between the rudder and the midship frame).

Electric propeller plant control.

Control is carried out from a control post $(C P)$ on the bridge. The main task is to control the movement of the vessel in real time. The $C P$ output signal generates two control actions - in frequency $\alpha$ and in voltage $\gamma$.

The relative frequency of the output voltage of the frequency converter is 


$$
\begin{gathered}
\alpha=\alpha_{S e t}-K_{\alpha P} \alpha_{P}-K_{\alpha \omega} \alpha_{\omega}-K_{\alpha f}\left(\alpha_{f}-\alpha_{f \max }\right)-K_{\alpha M}\left(\alpha_{M}-\alpha_{M \max }\right)- \\
-K_{\alpha I}\left(\alpha_{I}-\alpha_{I \text { max }}\right)-K_{\alpha P D}\left(\alpha_{P D}-\alpha_{P D \max }\right)
\end{gathered}
$$

where $\alpha_{S e t}-$ is the reference value of the relative frequency; $\alpha_{P}$ - corrective correlation according to the $P M$ power; $\alpha_{\omega}$-corrective relationship for the $P M$ angular rotation speed; $\alpha_{\mathrm{f}}-$ is the cut-off at the output frequency of the frequency converter; $\alpha_{M}-$ is the cut-off by the $P M$ torque; $\alpha_{I}-$ is the cutoff current of the $P M$ stator; $\alpha_{P D}$ - cut-off by the power consumed by the electric propulsion system; $K_{\alpha P}, K_{\alpha \omega}, K_{\alpha f}, K_{\alpha M}, K_{\alpha I}, K_{\alpha P D}$ - gain factors, which are determined by a specific control system.

Relative voltage at converter output

$$
\gamma=\gamma_{S e t}-K_{\gamma I}\left(\gamma_{I}-\gamma_{I \max }\right)-K_{\gamma U} \gamma_{U},
$$

where $\gamma_{S e t}-$ is the reference value of the relative voltage at the converter output - a signal that is a function of the relative frequency and the adopted law of voltage control; $\gamma_{U}$-is the corrective relation for the $P M$ voltage $\gamma_{I}-$ is the cutoff current of the $P M$ stator; $K_{\gamma I}, K_{\gamma U}$ - are gain factors.

In each case, the automatic control system has its own "set" of control signals for each control channel. It is these control actions that directly affect the quality indicators of the vessel performing maneuvering operations.

The developed mathematical model allows us to comprehensively analyze transients in propulsive complexes of electric ships on maneuvers. The enlarged calculation algorithm is: found;

- the dimensionless parameters of the components of the complex are

- for the calculated maneuvers, the basic control parameters are set, respectively, to the position of the control post handles and the rudder shift;

- initial conditions are set;

- control signals for each power circuit are generated;

- current values of the operational indicators of each power circuit of the electric power plant are calculated (during the maneuver);

- hydrodynamic forces and moments acting on the vessel are determined; the current values of the vessel motion parameters are calculated in the coordinate system associated with the vessel, and then in the coordinate system unrelated to the vessel.

During the calculation, the current values of the operational indicators of the complex are searched in the course of the maneuvers and the main indicators of the quality of maneuvering are assessed. The final calculation results are presented in numerical form and in the form of ready-made graphs of the time changes of the main operational indicators: 
a) on each power circuit:

- the angular velocity of rotation of the heat engine $-\omega_{D}$;

- torque of the heat engine $-M_{D}$;

- heat engine power $-P_{D}$;

- voltage at the output of the generator $-U_{G}$;

- generator current $-I_{G}$;

- generator excitation current $-\underline{I}_{f G}$;

- the relative value of the voltage at the output of the converter is $-\gamma$;

- voltage of the propeller motor $-U_{M}$;

- current of the propeller motor $-I_{M}$;

- torque of the propeller motor $-M_{M}$;

- angular rotation speed of the propeller motor $-\omega_{M}$;

b) the parameters of the vessel:

- a component speed of movement along the longitudinal axis $X-v_{X}$;

- a component speed of movement along the transverse axis $Y-v_{Y}$;

- speed of movement $-v$;

- angular speed of rotation (speed of rotation) of the vessel around the axis $Z-\Omega_{Z}$;

- drift angle $-\beta_{D R}$;

- ship heading angle $-\psi$.

As an example, in Fig. 2 some results of calculations of one of the characteristic maneuvers are given - acceleration of the propulsive complex and the vessel entering the circulation, while simultaneously shifting the rudder and braking one of the propellers.

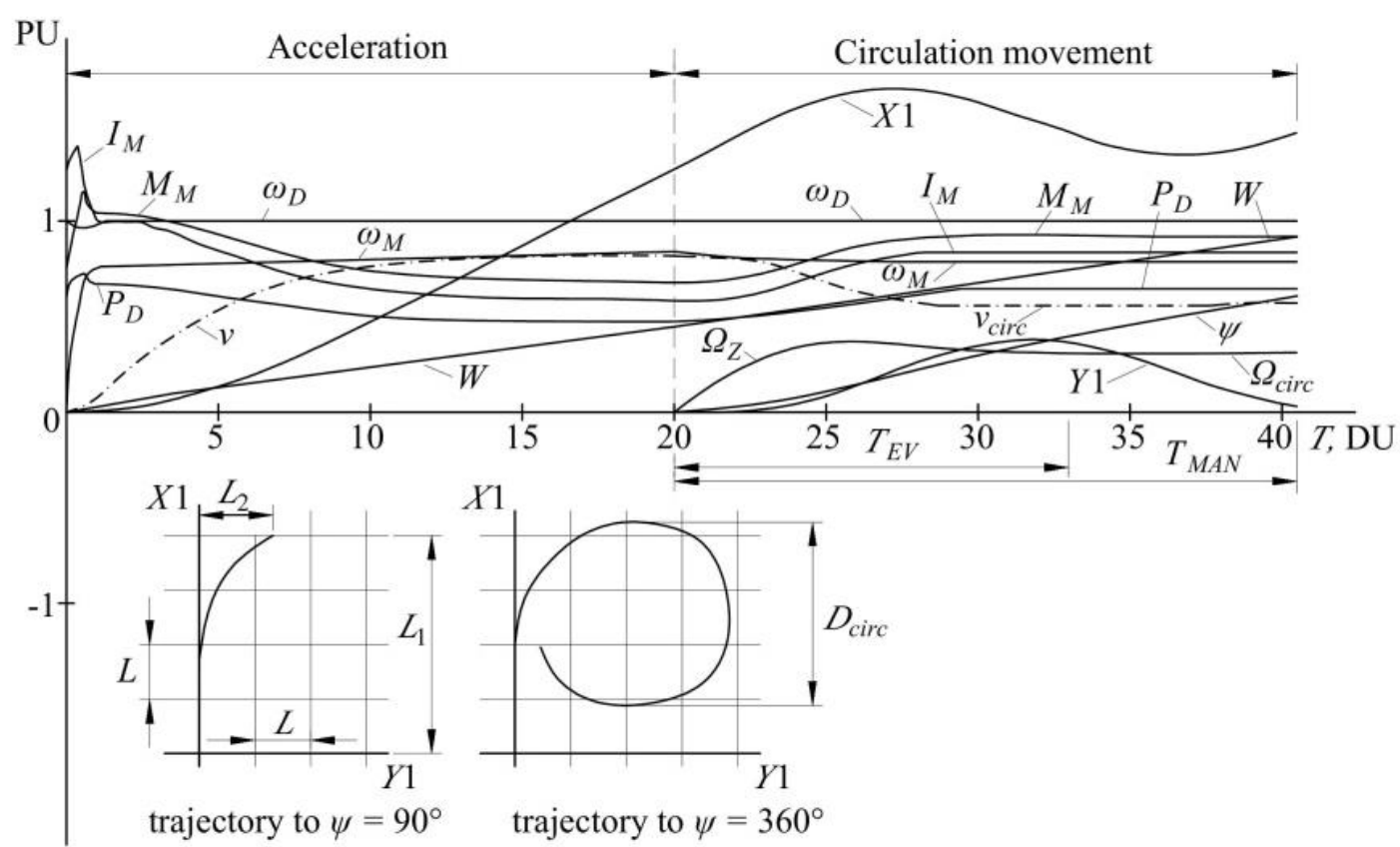

Fig. 2. Acceleration of the propulsion system and the vessel's circulation 
In the initial state, the vessel is motionless, generator sets are idling. The maneuver begins with the appearance of a control signal at a frequency $\alpha$ supplying voltage electric motors. Acceleration of the propeller motor begins. Its torque $M_{M}$ increases the rotational speed of the engine and the propeller $\omega_{M}$ increase. The thrust of the rudders increases, the electric ship begins to accelerate. With increasing $\omega_{M}$ and speed $v$ of the vessel, the moment of resistance of the propeller $M_{P}$, the current of the motor $I_{M}$ and its moment $M_{M}$ increase. The load on the heat engine is increasing. Its power $P_{D}$ increases, and the rotation frequency $\omega_{D}$ drops slightly. Energy (fuel) consumption $W$ is growing. After 12-13 (in the described maneuver) of relative units of time, the transition process ends, and the propulsive complex enters an operating mode close to the established one. The distance covered during the maneuver is described by curve $X 1$.

From the moment of time $T=20$, the process of the ship's embarkation on a curved path begins. The loads on the propeller motors and on the heat engines of the generating sets increase $\left(I_{M}, M_{M}, P_{D}\right.$ increase, $\omega_{M}$ decreases). The electric ship goes into circulation. The angular velocity $\Omega_{Z}$ of rotation and the transverse displacement $Y 1$ appear. The speed of the vessel $v$ decreases. Around $\mathrm{T}=33$, the evolutionary stage of the circulation movement ends and its quasi-steady period begins. The maneuver ends when the ship enters the course $\psi=360^{\circ}$. The electric ship's trajectory of the center of gravity is shown in Fig. 2 (a slight shift in the opposite direction at the beginning of the circulation is not shown). The total duration of the maneuver is $T=41$ relative units of time.

The ability to calculate the current values of operational indicators allows analyzing the behavior of all the components of the complex on maneuvers, evaluating their dynamics and taking measures to improve the dynamic performance indicators. However, individual performance indicators of the components of a propulsive complex are of greater value for comparative evaluations of performance indicators for performing maneuvering operations, for improving dynamic performance indicators, and for improving reliability indicators during maneuvering operations. First of all, these are the indicators of maneuverability of the electric ship itself and economic indicators of the performance of maneuvering operations, the load on heat engines and propeller motors.

An analysis of the results of numerous calculations, the existing practice of designing and operating ships with electric propulsion give reason to propose the following indicators for evaluating their maneuvering properties.

When maneuvering on a straight path:

- time of maneuver performance $T$;

- fuel costs for maneuver $W$; 
- fluctuations in the angular rotation velocity of heat engines

$$
\Delta \omega_{D}=\frac{\omega_{D \max }-\omega_{D \min }}{\omega_{D \text { std }}}
$$

- maximum power of heat engines $P_{D m}=P_{D \text { max }} / P_{D s t d}$;

- bursts of generators current during acceleration $\left(I_{G}\right)_{A c c} \mathrm{~m}$ and reverse $\left(I_{G}\right)_{R e v \mathrm{~m}}$

$$
\left(\mathrm{I}_{\mathrm{G}}\right)_{\text {Acc } \mathrm{m}}=\left(\mathrm{I}_{\mathrm{G}}\right)_{\text {Acc max }} /\left(\mathrm{I}_{\mathrm{G}}\right)_{\text {Acc std }},\left(\mathrm{I}_{\mathrm{G}}\right)_{\operatorname{Rev} \mathrm{m}}=\left(\mathrm{I}_{\mathrm{G}}\right)_{\text {Rev m }} /\left(\mathrm{I}_{\mathrm{G}}\right)_{\text {Rev std. }} ;
$$

- steady-state current values of the generators during acceleration $\left(I_{G}\right)_{R e v}$ std. and reverse $\left(I_{G}\right)_{R e v ~ s t d ;}$

- voltage drop at the output of the generators $\Delta U_{G}=\frac{U_{G \max }-U_{G \min }}{U_{G \text { std }}}$;

- the duration of acceleration $T_{M A c c}$ and reverse $T_{M R e v}$ GED and propellers;

- surges (surges) of the PM current during acceleration $\left(I_{M}\right)_{\mathrm{Pm}}$ and during reverse $\left(I_{M}\right)_{\mathrm{Tm}}$

$$
\left(\mathrm{I}_{\mathrm{M}}\right)_{\text {Acc } \mathrm{m}}=\left(\mathrm{I}_{\mathrm{M}}\right)_{\text {Acc max }} /\left(\mathrm{I}_{\mathrm{M}}\right)_{\text {Acc std }},\left(\mathrm{I}_{\mathrm{M}}\right)_{\text {Acc } \mathrm{m}}=\left(\mathrm{I}_{\mathrm{M}}\right)_{\text {Rev max }} /\left(\mathrm{I}_{\mathrm{M}}\right)_{\text {Rev std }} ;
$$

- bursts (throws) of the PM torque during acceleration $\left(M_{M}\right)_{A c c} m$ and during reverse $\left(M_{M}\right)_{A c c m}$

$$
\left(\mathrm{M}_{\mathrm{M}}\right)_{\text {Acc } \mathrm{m}}=\left(\mathrm{M}_{\mathrm{M}}\right)_{\text {Acc max }} /\left(\mathrm{M}_{\mathrm{M}}\right)_{\text {Acc std. }},\left(\mathrm{M}_{\mathrm{M}}\right)_{\text {Acc } \mathrm{m}}=\left(\mathrm{M}_{\mathrm{M}}\right)_{\text {Rev max }} /\left(\mathrm{M}_{\mathrm{M}}\right)_{\text {Rev std. }} \text {; }
$$

- steady-state values of the PM torque during acceleration $\left(M_{M}\right)_{\mathrm{P}}$ std and during reverse $\left(M_{M}\right)_{T s t}$;

- steady-state values of the angular rotation speed of the PM and propellers during acceleration $\left(\omega_{M}\right)_{A c c}$ std. and with reverse $\left(\omega_{M}\right)_{\text {Rev std.; }}$;

- the duration of transient processes in a power plant during acceleration $\left(T_{P E P P}\right)_{A c c .}$ and reverse $\left(T_{P E P P}\right)_{\text {Rev }}$;

- maximum vessel speed at the end of acceleration $v_{\max }$;

- duration of the propulsive complex acceleration to a given speed value $(T)_{V=V s t d}$;

- distance travelled by the ship at the end of the maneuver $(X 1)_{A c c}$ or $(X 1)_{\text {Rev }}$.

During circulating movement:

- changes in the power of the primary engines of the external $\left(\Delta P_{D}\right)_{1}$ and internal $\left(\Delta P_{D}\right)_{2}$ with respect to the circulation centre of the energy circuits, when the electric ship enters a steady circulation

$$
\left(\Delta P_{D}\right)_{1}=P_{D 1} / P_{D s t d .},\left(\Delta P_{D}\right)_{2}=P_{D 2} / P_{D s t}
$$


- changes in the stator current PM external $\left(\Delta I_{M}\right)_{1}$ and internal $\left(\Delta I_{M}\right)_{2}$ energy circuits $\left(\Delta I_{M}\right)_{1}=I_{M 1} / I_{M s t d .},\left(\Delta I_{M}\right)_{2}=I_{M 2} / I_{M s t d}$;

- changes in the PM torque of the external $\left(\Delta M_{M}\right)_{1}$ and internal $\left(\Delta M_{M}\right)_{2}$ energy circuits $\left(\Delta M_{M}\right)_{1}=M_{M 1} / M_{M s t d .},\left(\Delta M_{M}\right)_{2}=M_{M 2} / M_{M s t d}$;

- changes in the angular velocity of rotation of the PM and the propellers of the external $(\Delta \omega)_{1}$ and internal $(\Delta \omega)_{1}$ energy circuits

$\left(\Delta \omega_{M}\right)_{1}=\Delta \omega_{M 1} / \Delta \omega_{M s t d} ;\left(\Delta \omega_{M}\right)_{2}=\Delta \omega_{M 2} / \Delta \omega_{M s t d} ;$

- reduction in the vessel speed with its exit to the steady circulation $(\Delta v)_{C I R C}=v_{C I R C} / v_{\text {std. }}$;

- angular speed of rotation of the vessel $\Omega_{Z}$ at a steady circulation $\Omega_{C I R C}$;

- circulation diameter $D_{\text {CIRC; }}$;

- tactical diameter of the circulation $D_{C I R C \text { i }}$;

- extension of the vessel $L_{1}$;

- direct displacement of the vessel $L_{2}$;

- course angle of the vessel after a specified period of time $\psi_{C I R C}$;

- duration of the full revolution $T_{\text {CIRC; }}$;

- duration of the evolutionary period of the maneuver $T_{\text {CIRC } 2 \text {; }}$;

- fuel costs for the vessel to complete the full turnover of $W_{C I R C}$.

The designation "STD" in the indices of indicators describing the circulation movement means the initial (at the time of going to circulation) value of the corresponding indicator.

Most of the proposed quality indicators are determined directly from the current dependences of operational indicators obtained during the calculations (Fig.2) or from the trajectories of the vessel. Some are found using additional calculations. In particular, the relative fuel costs $\mathrm{W}$ for maneuvering are determined similarly to how it was done in

$$
W=\int_{0}^{T} g_{e}^{0} M_{D}^{0} \omega_{D}^{0} d T
$$

where $g_{e}^{0}=\frac{g_{e}}{g_{e 0}}-$ is the relative current specific fuel consumption.

The totality of these indicators (and more than 40 of them are proposed), as it can be assumed, sufficiently covers each element of the electric ship power plant individually and the whole electric ship as a whole, and has the necessary sufficiency to assess the dynamics and maneuverability of propulsion systems. 


\section{PART 2. OPTIMAL DESIGN OF PROPELLER ELECTRIC POWER PLANTS}

A comprehensive assessment of the design quality of ship electric power plants involves parametric optimization according to the main optimality criteria. For electric ships, these are indicators of the quality of performing maneuvering operations. All of them can be divided into two groups:

1. The eldest, which includes indicators characterizing the vessel (as a system of a higher level), its maneuverability, maneuvering safety, economic performance. They are:

- the duration of the maneuver $T$;

- the path traveled by the ship - stopping $X$;

- the relative fuel consumption for the maneuver $W$.

2 . The youngest, characterizing the maneuvering properties of the electric power plant, its components (primarily heat engines and propeller motors), the duration and quality of transient processes in the PEPP. They include:

- fluctuations in the angular rotation speed of heat engines $\Delta \omega_{D}$;

- maximum power increment of $P_{D \max }$ heat engines;

- duration of $P M$ reverse $T_{M r e v}$ and propellers;

- the duration of the transient processes in the propelling electric power plant during reverse $\left(T_{P E P P}\right)_{\text {rev }}$.

In accordance with a systematic approach, the older group takes precedence over the younger.

The parametric optimization process consists of two stages.

Stage 1 . The number of parameters $n$ that affect the quality indicators of maneuvering is hundreds. It is possible to reduce their number to several tens by translating the equations of the mathematical model to a system of dimensionless units and highlighting the generalized dimensionless parameters (similarity criteria) of propulsive complexes. However, even after this procedure, the number of parameters remains too large. At the same time, it is known that in the objects under consideration no more than 6-10 parameters have a significant impact on design quality indicators. Therefore, at the first stage of optimization, the task is to identify those parameters and those effects of parameter interactions whose influence is significant.

In other words, from the set of parameters $q_{i}, i=1, \ldots, n$ of the optimized multidimensional space En, it is necessary to select a subset of parameters $p$ $(p<n)$, the deviation of which from the calculated values $\Delta q_{j}$ determines the main part of the increment of the quality indicator $J\left(\Delta q_{j}\right) \approx J\left(\Delta q_{i}\right)$. These parameters are subject to optimization. The scatter of the remaining $s=n-p$ parameters does not have a significant effect on the indicator under study, and it is advisable to take their values as non-invariable. It should be understood 
that for each optimality criterion there will be its own set of significant parameters.

The solution to this problem is carried out by the methods of screening experiments ${ }^{9}$. If the number of factors is several tens, it is convenient to use the random balance method. It allows for each indicator of the quality of the maneuver to identify significant parameters and the effects of parameter interactions. The contribution of each factor is determined by the results of numerical experiments conducted on pre-planned matrices. The significance level of each parameter is estimated by the results of statistical analysis carried out at each stage of the calculation.

Such studies as applied to the main maneuvers of electric ships acceleration, deceleration, reverse, and access to circulation are presented in the article ${ }^{10}$. It is shown that for each of the selected quality indicators there is its own set of significant parameters.

A comprehensive analysis of the degree of their influence was carried out. As a result, it was possible to identify those parameters whose contributions to the selected indicators are most significant. These parameters are given in table. 1 .

Table 1

\section{Contributions of significant parameters} to maneuvering performance indicators

\begin{tabular}{|c|c|c|c|c|c|c|c|}
\hline \multirow{2}{*}{ Parameter } & \multicolumn{7}{|c|}{ Contribution to quality indicators, \% } \\
\cline { 2 - 8 } & $T_{\min }$ & $W_{\min }$ & $X 1_{\min }$ & $\Delta \omega_{D}$ & $P_{D \max }$ & $T_{\text {Mrev }}$ & $T_{\text {PEPPrev }}$ \\
\hline$N_{X}$ & 38,4 & 26,6 & 29 & - & - & 14,7 & 13,4 \\
\hline$C_{M 16}$ & 28,7 & 10,7 & 26,3 & 13,8 & 27,6 & 22,5 & 18,7 \\
\hline$C_{M 20}$ & 12,9 & 11,3 & 21,5 & - & 13,6 & 17,5 & 7,4 \\
\hline$C_{M 18}$ & 5,9 & 6,3 & - & - & - & - & - \\
\hline$C_{M 23}$ & 3,3 & $C_{\mathrm{M} 17}$ & 19,3 & - & 17,8 & - & - \\
\hline$C_{M 17}$ & $\mathrm{C}_{\mathrm{M} 17}$ & 16,5 & - & 14 & 15,3 & & 7,4 \\
\hline$C_{G 7}$ & 2,5 & - & - & - & 20,5 & 29,8 & 7,4 \\
\hline$C_{M 21}$ & - & 1,7 & - & - & - & - & - \\
\hline
\end{tabular}

${ }^{9}$ Chernikov P. S., Yarovenko V. A., Zaritskaya E. I. (2018) Vliyanie parametrov elektrokhodov na pokazateli kachestva raboty elektroenergeticheskikh ustanovok pri manevrirovanii [The influence of parameters of electric ships on the performance indicators of electric power plants during maneuvering]. News of the National Technical University "KhPI". Seriya: "Electric machines and electric energy redesign". Kh.: NTU "KhPI", 2018. No. 5 (1281). Pp. 46-54.

10 Yarovenko V. A., Chernikov P. C., Varbanets R. A., Zaritskaya E. I. (2018) Optimal'noe upravlenie propul'sitvnymi kompleksami elektrokhodov pri reversirovanii [Optimal control of propulsion systems of electric ships during reversing]. Electrical engineering and electrical engineering. 2018. No. 6. Pp. 38-46. DOI: 10.20998/2074272X.2018.6.05. 
Table 1 (ending)

\begin{tabular}{|c|c|c|c|c|c|c|c|}
\hline \multirow{2}{*}{ Parameter } & \multicolumn{7}{|c|}{ Contribution to quality indicators, \% } \\
\cline { 2 - 8 } & $T_{\min }$ & $W_{\min }$ & $X 1_{\min }$ & $\Delta \omega_{D}$ & $P_{D \max }$ & $T_{\text {Mrev }}$ & $T_{\text {PEPPrev }}$ \\
\hline$N_{M}$ & - & - & 3,5 & - & - & - & - \\
\hline$N_{D}$ & - & - & - & 26 & - & - & 9,3 \\
\hline$c_{D P}$ & - & - & - & 25,4 & - & - & - \\
\hline$C_{G 8}$ & - & - & - & 13,3 & - & 10,6 & - \\
\hline$C_{G 10}$ & - & - & - & 6,3 & - & - & - \\
\hline$C_{M 38}$ & - & - & - & - & - & 9,8 & - \\
\hline$k 2$ & - & - & - & - & - & - & 34,4 \\
\hline
\end{tabular}

The generalized dimensionless parameters given in table. 1, are calculated by the ratios:

$$
\begin{gathered}
C_{G 7}=\frac{K_{G E} W_{G V}}{E_{G 0}} \omega_{D 0} I_{G V 0} ; \quad C_{G 8}=\frac{K_{G E} \omega_{D 0}}{E_{G 0}} \frac{m_{G} \sqrt{2}}{\pi} \frac{W_{G 1} k_{G B}}{p_{G}} I_{G 0} ; \quad C_{G 10}=\frac{U_{G 0}}{E_{G 0}} ; \\
C_{M 16}=\frac{\beta_{M 0}}{r_{M}^{\prime 2}}\left[\left(b_{M}^{2}+c_{M}^{2} \alpha_{0}^{2}\right)+\left(d_{M}^{2}+e_{M}^{2} \alpha_{0}^{2}\right) \frac{r_{2 M}^{\prime 2}}{\beta_{M 0}^{2}}+2 r_{1 M} \alpha_{0} \frac{r_{2 M}^{\prime}}{\beta_{M 0}}\right] ; \quad C_{M 17}=\frac{b_{M}^{2}}{\left(r_{2 M}^{\prime}\right)^{2}} ; \\
C_{M 18}=\frac{c_{M}^{2}}{r_{2 M}^{\prime 2}} \alpha_{0}^{2} ; \quad C_{M 20}=\frac{\omega_{M 0}}{\omega_{1 M H}} ; \quad C_{M 21}=d_{M}^{2} ; \quad C_{M 23}=2 \frac{r_{1 M}}{r_{2 M}^{\prime}} \alpha_{0} ; \\
N_{X}=\frac{L P_{e 0}}{\left(m+\lambda_{11}\right) \nu_{0}^{2}}, \quad N_{M}=\frac{M_{M 0} L}{J_{M} \omega_{M 0} v_{0}} ; N_{D}=\frac{M_{D 0} L}{J_{D} \omega_{D 0} v_{0}} ;
\end{gathered}
$$

where $\omega_{D 0}$ - is the angular velocity of rotation of the prime mover; $I_{G V 0}-$ is excitation current of a synchronous generator; $U_{G 0}$ and $I_{G 0}$ - are voltage and current of the generator; $K_{G E}, m_{G}, W_{G 1}, k_{G B}, p_{G}$ и $W_{G V}$-are design parameters of the generator; $E_{G 0}$ - is the longitudinal component of the resulting EMF of the generator; $\omega_{M 0}$ and $\omega_{1 M_{\mathrm{H}}}-$ are the angular rotational speeds of the motor and the stator magnetic field at the nominal frequency; $\beta_{M 0}-$ is the PM absolute slip of the rotor; $\alpha_{0}-$ is the PM relative frequency of voltage; $r_{1 M}$ and $r_{2 M}{ }^{\prime}$ - are the stator resistance and the reduced resistance of the PM rotor; $b_{M}$, $c_{M}, d_{M}, e_{M}-$ constant coefficients of a frequency-controlled asynchronous electric motor; $m$ and $\lambda_{11}-$ are the mass of the vessel and the attached masses of water along its longitudinal axis; $P_{e 0}-$ is the net total thrust of the propellers; $L$ - is the length of the vessel; $M_{D 0}, M_{M 0}$ - is the torque of the prime mover and PM; $J_{D}, J_{M}$ - are the moments of inertia of the rotating parts reduced to the primary engine shaft and to the PM shaft (index " 0 " refers to the basic operation mode corresponding to the movement of the vessel with rated engine power); 
$c_{D P}$ - statism of the regulatory characteristic of primary engines;

$k 2$ - is a coefficient characterizing the slew rate of the voltage of the propeller motors during braking.

The effect of the parameters given in table 1 is significant. These are parameters that make sense to optimize.

Stage 2. Target functions of optimization calculations, as a rule, are multicriteria. Consequently, performance indicators of maneuvers $J_{j}$ must be included in them $J=\sum_{j} m_{j} J_{j}$ with their weight contributions $m_{j}$. The criteria are often contradictory, therefore, it is necessary to clearly substantiate the choice of their weight coefficients. Typically, in such cases, a number of significant problems arise related to the goals, expert estimates of weight contributions, scaling of quality indicators, organization of the computational procedures themselves, etc.

As preliminary calculations showed, by dividing the quality indicators into the senior and younger groups, it is possible to facilitate the tasks being solved, without substantially worsening the result of their solution.

In accordance with the systematic approach, optimization should be carried out first according to the indicators of the senior group, and then, adhering to the principles of non-deterioration taking into account the specified tolerance of the indicators of the senior group, according to the indicators of the younger group.

We will illustrate the feasibility of such an optimization strategy and the mathematical apparatus capabilities using the example of the search procedure for the best option for constructing the electric ship propulsion complex, providing a minimum of the duration of the maneuver $T_{\min }$ and the fuel consumption for its implementation $W_{\min }$. As a rule, these indicators are mutually contradictory. The search for optimal parameters should be carried out by a multicriteria objective function

$$
J_{T G}=m_{T} T+m_{W} W,
$$

where $m_{T}$ and $m_{W}-$ are the weights of the corresponding indicators.

In the course of parametric optimization, one has to constantly face the need for informal procedures. The main reasons for this include the following.

1. The ratio of weights $m_{T}$ and $m_{W}$ affects the optimal solution. As a rule, this ratio is not known in advance and in each case is selected depending on the goal.

2. Optimization by individual maneuvers gives different results. As a result, it is necessary to make compromise decisions which, to a greater or lesser extent, satisfy the goal. 
The results of such optimization calculations performed for various relations between the weight coefficients $m_{T}$ and $m_{W}$, are given, in particular, in the article $^{11}$ and can be used for parametric optimization of electric ships propulsive complexes.

You can specify the values of optimized parameters by indicators of the younger group. Such optimization, taking into account the "non-deterioration" (with a given tolerance) of the indicators of the senior group makes it possible, on the one hand, to improve the performance of the power plant, and on the other hand, not to significantly degrade the quality indicators of the senior group. In this case, it is advisable to search for optimal parameters by a multicriteria objective function of the type

$$
J_{T P \omega}=m_{T} T_{\text {рев }}+m_{P} P_{D}+m_{\omega} \omega_{D} .
$$

As applied to the class of problems under consideration, a special optimization method was developed in $\operatorname{article}^{12}$. By their statement, these problems belong to the field of nonlinear programming and consist in finding extreme of multimodal objective functions $f(\boldsymbol{x})$ under given constraints $g_{j}(\boldsymbol{x})$ in the form of inequalities

$$
\left.\begin{array}{cc}
f(\mathbf{x}), & x \in \mathbf{E}^{n} ; \\
g(\mathbf{x}) \geq 0, & j=1, \ldots, p,
\end{array}\right\},
$$

where $\boldsymbol{E}^{n}$ - is the allowable region of the n-dimensional space of dimensionless parameters of the electric ship's propulsive complex.

The optimal solution will be a pair $\boldsymbol{x}_{*}$ and $f\left(\boldsymbol{x}_{*}\right)$, consisting of the optimal point $\boldsymbol{x}_{*}=\left[x_{1^{*}}, x_{2^{*}}, \ldots, x_{n^{*}}\right]$ (the set of optimal parameter values) and the corresponding value of the objective function $f\left(x_{*}\right)$

$$
\left.\begin{array}{c}
x_{*}=\left[x_{1^{*}}, x_{2^{*}}, \ldots, x_{n^{*}}\right] ; \\
f_{*}=f\left(x_{*}\right) .
\end{array}\right\} .
$$

The character of the objective functions has a fundamental influence on the development of an optimization method. As shown by numerous calculations,

11 Yarovenko V. A. (2000) Metody poiska optimal'nykh resheniy pri proektirovanii energeticheskikh ustanovok elektrokhodov [Methods of searching for optimal solutions in the design of power plants of electric ships]. Zb. sciences. pr. UDMTU. Mikolaev: UDMTU, 2000. No. 1 (367). Pp. 29-36.

12 Dorofeyev V. S., Pushkar N. V. (2018). Stojkost' betona gidrotehnicheskih sooruzhenij pri mnogokratnom uvlazhnenii i vysushivanii [Resistance of concrete of port structures with repeated wetting and drying]. Current scientific research in the modern world. Pereyaslov-Khmelnicki, Issue 4 (36), part 10, pp. 68-73. 
the considered objective functions $f(\boldsymbol{x})$ are multi-extreme with an unknown number of local optima. Therefore, the algorithms for finding optimal solutions were built on the principles of global optimization. The developed global optimization algorithms are based on the global random search method random multistart. In its pure form, random multi-start is inefficient, because when it is used, a large amount of unnecessary computational work is spent on repeated descents to the points of local minima. To prevent such descents, a combination of one of the passive coating methods - the random mesh method - with the modified tunnel algorithm method was introduced into the global optimization algorithm.

The choice of search methods for local optima (internal procedures of global optimization) is influenced by the pronounced ravine nature of the objective functions. Based on this, the search algorithm for intermediate local optima was created on the basis of a combination of local descent methods and ravine search methods.

The choice of methods for searching for local optima was carried out from the following considerations. The values of the objective functions are found as a result of the calculation of maneuvers described by a complex system of algebraic and differential equations with numerous constraints that ensure the normal functioning of the system. Deriving the objective function is unrealistic. Therefore, as algorithms for searching for local optimums, methods that did not use derivatives were chosen. The Powell and Nelder-Mead methods proved effective for solving the class of problems under consideration.

The methods used were combined with the methods of penalty functions, which allows us to reduce the nonlinear programming problem with restrictions to an equivalent sequence of problems without restrictions.

Optimization Results. The final values of the optimal parameters of propulsive complexes are given in table. 2 . They are obtained by the results of phased parametric optimization, first according to the criteria of the senior group, and then according to the criteria of the younger group (taking into account the accepted degree of significance of quality indicators). Optimization by the indicators of the senior group was carried out for the ratio of the weight contributions $m_{T}=0$ and $m_{W}=1$. Optimization by the indicators of the younger group was performed according to the multicriteria objective function with the ratio $J_{T P \omega}=m_{T} T_{\text {рев }}+m_{P} P_{D}+m_{\omega} \omega_{D}$ of the weight contributions $m_{\omega}=0,75, m_{P}=0,25, m_{T}=0$.

The effectiveness of parametric optimization by the developed methodology is illustrated by the example of a real ship. This is a project of an electric ship with the following basic parameters: vessel length $-52 \mathrm{~m}$; width $15 \mathrm{~m}$; displacement - $1763 \mathrm{t}$; power of the main engines - $2200 \mathrm{~kW}$; 
movement speed $-7 \mathrm{~m} / \mathrm{s}$. The electric propelling plant includes: two diesel generator sets with heat engines, an effective power of $1100 \mathrm{~kW}$ and synchronous generators with a power of $1000 \mathrm{~kW}$, at $750 \mathrm{rpm}$; frequency converters; two asynchronous propeller motors with a power of $1000 \mathrm{~kW}$. Propeller motors have the following main parameters: stator current $1100 \mathrm{~A}$; torque $10670 \mathrm{Nm}$; angular rotation speed $93,67 \mathrm{~s}^{-1}$; power factor 0,835 . Basic winding data: stator resistance $0,00419 \mathrm{Ohm}$; stator reactance $0,0879 \mathrm{Ohm}$; reduced rotor resistance of $0,0359 \mathrm{Ohms}$; reduced reactance of the rotor of 0,1319 Ohms; coefficient of resistance reduction 34,336; magnetization reactance of 1,503 ohms.

The numerical values of the main dimensionless parameters of this vessel are presented in the column "projectof" table. 3. The optimal parameter values are given in the optimal column.

Table 2

\section{Optimal parameters of electric ship's propulsive complexes}

\begin{tabular}{|c|c|c|c|c|}
\hline \multirow{2}{*}{$\begin{array}{c}\text { Parameters } \\
\text { complex }\end{array}$} & \multirow{2}{*}{$\begin{array}{c}\text { Ranges } \\
\text { changes }\end{array}$} & \multicolumn{2}{|c|}{$\begin{array}{c}\text { Optimization of parameters } \\
\text { by criteria }\end{array}$} & $\begin{array}{c}\text { Optimal } \\
\text { parameters }\end{array}$ \\
\cline { 3 - 5 } & $0,06-0,20$ & $J_{T W}$ & $J_{\omega P T}$ & \\
\hline$N_{X}$ & $0,8-1,6$ & 1,6 & 0,2 & 0,2 \\
\hline$C_{M 23}$ & $4-14$ & $7-9$ & 1,6 & 1,6 \\
\hline$C_{M 16}$ & $0,6-0,9$ & $0,6-0,9$ & 0,894 & 8,1 \\
\hline$C_{M 20}$ & $1-9$ & 5 & 5,85 & 0,9 \\
\hline$C_{M 18}$ & $0,2-0,8$ & $0,2-0,8$ & 0,785 & 5 \\
\hline$C_{M 17}$ & $1,5-1,9$ & $1,55-1,81$ & 1,81 & 1,81 \\
\hline$C_{G 7}$ & $0,86-1,35$ & $0,86-1,35$ & 1,338 & 1,1 \\
\hline$C_{G 8}$ & $1-6$ & $1-6$ & 4 & 3,5 \\
\hline$N_{D}$ & $1,035-1,065$ & $1,035-1,065$ & 1,039 & 1,04 \\
\hline$c_{D R}$ & $1,05-1,21$ & 1,1 & 1,1 & 1,1 \\
\hline$C_{M 22}$ & & & & \\
\hline
\end{tabular}

Table 3

Optimized parameters of the propulsion complex Project

\begin{tabular}{|c|c|c|c|c|c|c|}
\hline \multirow{2}{*}{ Parameter } & \multicolumn{2}{|c|}{ Parameter Values } & \multirow{2}{*}{ Parameter } & \multicolumn{2}{|c|}{ Parameter Values } \\
\cline { 2 - 3 } & "Project" & Optimal & & & "Project" & Optimal \\
\hline$N_{D}$ & 1,937 & 3,5 & & 1,016 & 0,5 \\
\hline$C_{D R}$ & 1,04 & 1,04 & & $C_{M 17}$ & & \\
\hline$C_{G 7}$ & 1,45 & 1,81 & & $C_{M 18}$ & 40,21 & 5 \\
\hline$C_{G 8}$ & 0,608 & 1,1 & & $C_{M 20}$ & 0,895 & 0,9 \\
\hline$N_{X}$ & 0,132 & 0,2 & & $C_{M 22}$ & 1,12 & 1,1 \\
\hline$C_{M 16}$ & 14,127 & 8,1 & & $C_{M 23}$ & 0,233 & 1,6 \\
& & $C_{M 24}$ & 12 & 5,55 \\
\hline
\end{tabular}


Figures 3 and 4 show the current dependences of the vessel's main operational indicators when it performs a combined maneuver PEPP acceleration - reverse to a complete stop of the vessel. Fig. 3 refers to a complex with real parameter values. Figure 4 shows the current values of operational indicators of the optimized propulsive complex.

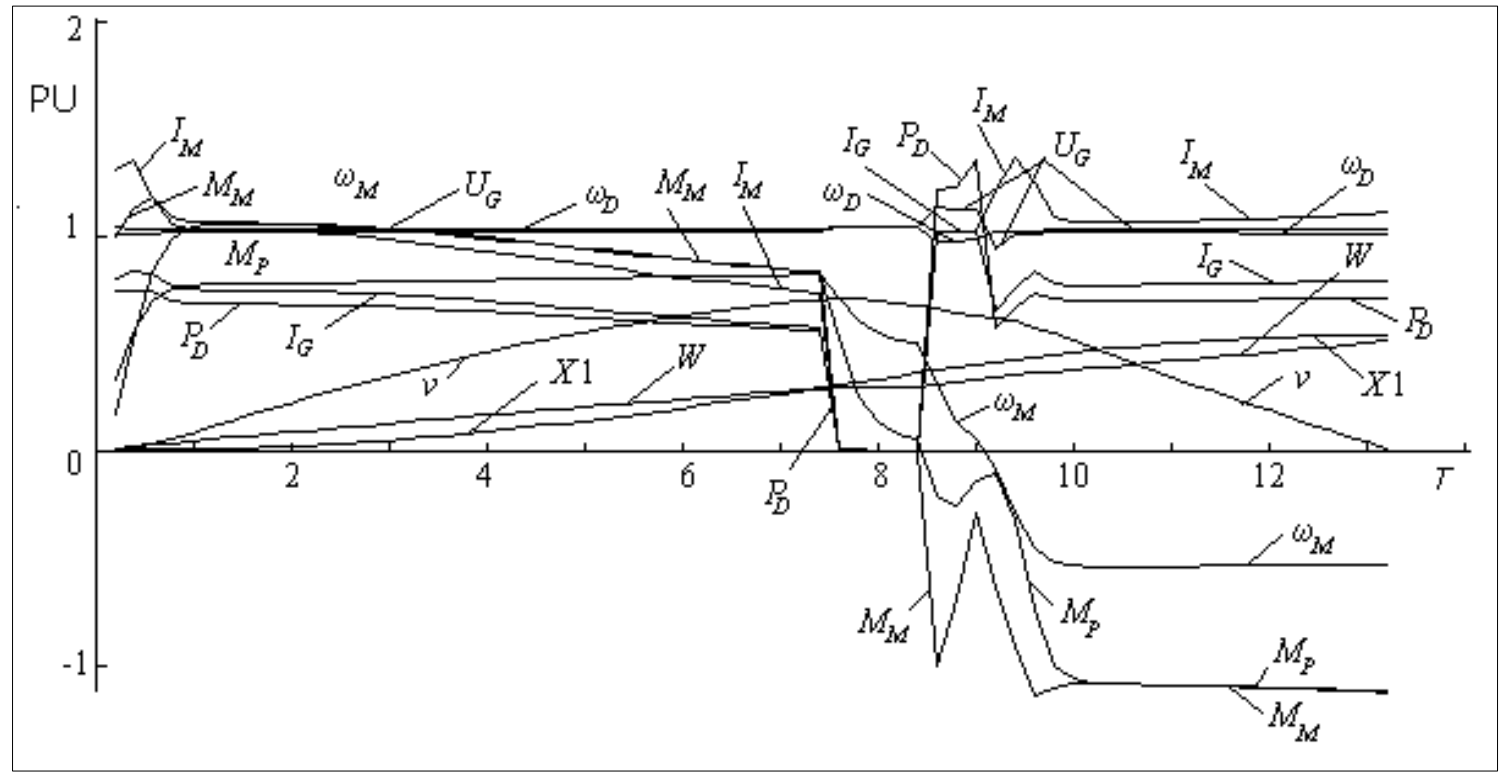

Fig. 3. Laws of change of operational indicators of the propulsive complex power plant Project

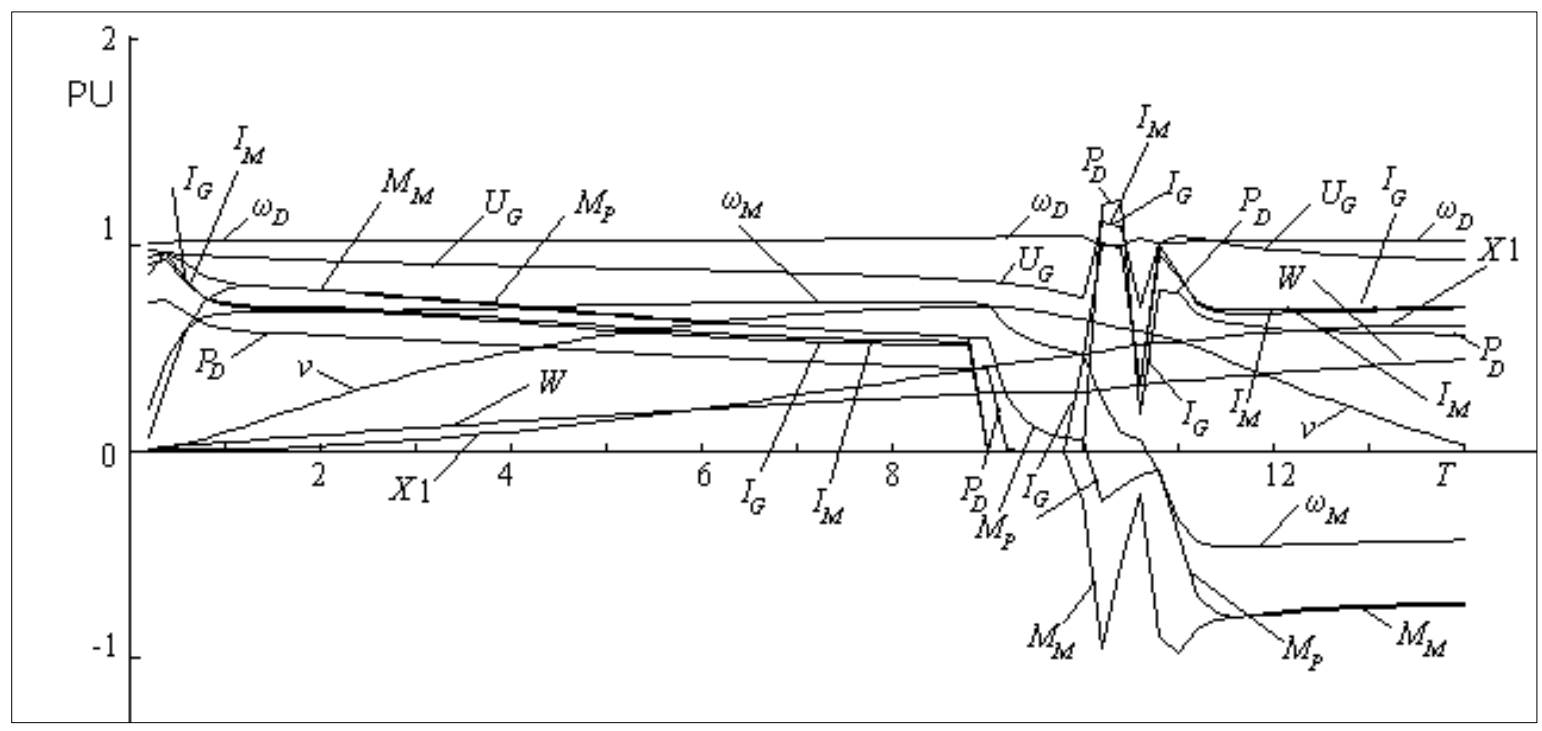

Fig. 4. Laws of change of power plant operational indicators of optimized version of the propulsive complex Project

The analysis of the results shows that the optimized electric ship has the following characteristics:

- fuel costs for maneuver decreased by $12,7 \%$; 
- the duration of the maneuver increased by $6 \%$;

- fluctuations in the rotational speed of heat engines decreased from 0.07 to 0,046 r.u., i.e. by $33,4 \%$;

- loads on heat engines during reverse decreased by $10,2 \%$;

- the PM duration of reverse increased by $3,1 \%$.

As you can see, three quality indicators improved, and two $-T$ and $T_{M r e v}-$ worsened. This is fully consistent with the target functions of the optimization task. The efficiency of the electric ship as a result of optimization has significantly increased. In addition, as can be seen from the figures, in a complex with an optimally designed power plant, transients are "softer".

\section{CONCLUSIONS}

1. The studies show that the traditional approach to the design of electric propelling plants does not allow fully providing electric maneuvers with high maneuverability. The reason is that the propelling plant is designed according to the performance indicators of the propelling electric power plant (PEPP) without taking into account the performance of the vessel. We need a systematic approach to designing a propelling electric power plant. It opens up wide opportunities for increasing the efficiency of propulsion systems. In this case, electric indicators fade into the background. It is necessary to design a propelling electric power plant in such a way as to ensure the best maneuverable properties of electric ships, with the performance indicators controlled by its propeller electric power plant.

To solve such problems, a PEPP should be considered together with all the components of a single ship propulsion complex, which includes propellers, the rudder and the hull of the vessel. The developed method for calculating operational indicators and the optimization method make it possible to achieve the goal.

2. Optimization calculations were carried out and optimal parameters of propulsive complexes providing high maneuverability characteristics of electric ships were found. The optimization efficiency is high. Depending on the goals set, it can reach $10-13 \%$. Thus, as shown in this paper, with the correct organization of the design process for a propeller electric power plant, it is possible to achieve high maneuvering characteristics of electric vessels and, at the same time, ensure that all components of a propeller electric power plant operate in acceptable modes.

\section{SUMMARY}

Comparative assessments of the design quality of electric ships propeller electric power plants (PEPP) should be carried out primarily according to the criteria of the vessel, in particular, according to its maneuverable characteristics. With this approach, design is carried out according to the final 
result. This contributes to the creation of reliable maneuvering vessels. For this, the propeller electric power plant should be considered together with the propellers, rudder and hull. This is a single (propulsive) complex. The block diagram of the complex is proposed. A mathematical model has been developed for calculating the current values of its operational indicators during maneuvering. The main indicators of the quality of performing maneuver operations are proposed. They cover all the components of the complex. The indicators, by which the maneuverable characteristics of the electric ship on the maneuvers are evaluated, were selected as the main indicators of quality. At the same time, the operation parameters of the PEPP are monitored. Parametric optimization is carried out. The optimal parameters of the complex are found. The optimization efficiency is illustrated.

\section{REFERENCES}

1. Nebesnov V. I. (1965) Voprosy sovmestnoy raboty dvigateley vintov i korpusa sudna [Issues of joint work of propeller engines and hull]. L.: Shipbuilding, 1965. $247 \mathrm{p}$.

2. Himmelblau D. (1975) Prikladnoe nelineynoe programmirovanie [Applied nonlinear programming]. M.: Mir, 1975. 534 p.

3. Yarovenko V. A. (1999) Raschet i optimizatsiya perekhodnykh rezhimov propul'sivnykh kompleksov elektrokhodov [Calculation and optimization of transient modes of propulsive complexes of electric ships]. Odessa: Lighthouse, 1999. 188 p.

4. Yarovenko V. A., Chernikov P. C. (2017) Metod rascheta perekhodnykh rezhimov grebnykh elektroenergeticheskikh ustanovok elektrokhodov [The method of calculating the transitional regimes of rowing electric power plants of electric ships]. Electrotechnika i elektromekhanika. 2017. No. 6. pp. 32-41. doi: 10.20998/2074-272X.2017.6.05.

5. Yarovenko V. A., Zaritskaya E. I., Chernikov P. C. (2017) Otsenka manevrennykh kharakteristik elektrokhodov na nachal'nykh stadiyakh ikh proektirovaniya [Assessment of the maneuverability characteristics of electric ships at the initial stages of their design]. Visnik NTU "KhPI". Seriya Electric Machines and Electric Power Engineering. Kharkiv: NTU KhPI, 2017. No. 1 (1223). Pp. 57-63.

6. Pershits R. Ya. (1983) Upravlyaemost' i upravlenie sudnom [Manageability and control of the vessel]. L.: Shipbuilding, 1983. 272 p.

7. Yarovenko V. A., Zaritskaya E. I. (2014) Cposob otsenki nagruzok na grebnye elektricheskie ustanovki elektrokhodov pri tsirkulyatsionnom dvizhenii [A method for assessing the loads on rowing electric installations of electric ships during circulation movement]. News of the Odessa Sovereign Morsky University. Odessa: ONMU. 2014. No. 1 (40). Pp. 89-103. 
8. Zubarev Yu. A., Sobashnikov A. D., Yukhnovich V. A. (1976) Raschet sudovykh avtomatizirovannykh sistem metodom aktivnogo planirovaniya eksperimenta [Calculation of shipboard automated systems by the method of active experiment planning]. L.: Shipbuilding. 1976. 96 p.

9. Chernikov P. S., Yarovenko V. A., Zaritskaya E. I. (2018) Vliyanie parametrov elektrokhodov na pokazateli kachestva raboty elektroenergeticheskikh ustanovok pri manevrirovanii [The influence of parameters of electric ships on the performance indicators of electric power plants during maneuvering]. News of the National Technical University "KhPI". Seriya: Electric machines and electric energy redesign. Kh.: NTU KhPI, 2018. No. 5 (1281). Pp. 46-54.

10. Yarovenko V. A. (2000) Metody poiska optimal'nykh resheniy pri proektirovanii energeticheskikh ustanovok elektrokhodov [Methods of searching for optimal solutions in the design of power plants of electric ships]. Zb. sciences. pr. UDMTU. Mikolaev: UDMTU, 2000. No. 1 (367). Pp. 29-36.

11. Yarovenko V. A., Chernikov P. C., Varbanets R. A., Zaritskaya E. I. (2018) Optimal'noe upravlenie propul'sitvnymi kompleksami elektrokhodov pri reversirovanii [Optimal control of propulsion systems of electric ships during reversing]. Electrical engineering and electrical engineering. 2018. No. 6. Pp. 38-46. doi: 10.20998 / 2074-272X.2018.6.05.

\section{Information about the author: Yarovenko V. A.,} Doctor of Technical Sciences, Professor, Head of the Department of Ship Electrical Equipment Operation and Automation, Odessa National Maritime University 34, Mechnikov str., Odessa, 65029, Ukraine ORCID ID: orcid.org/0000-0003-3183-6583 